\title{
Gender equality-the need of the hour
}

\author{
${ }^{1}$ S. Shanthi and ${ }^{2}$ Kakarla Sai Mitravinda \\ ${ }^{1}$ Assistant Professor, Dept. of English, PSG College of Arts and Science, Bharathiyar University, Coimbatore, TamilNadu, India-641014. \\ ${ }^{2}$ Bachelors of Science (Statistics), PSC College of Arts and Science, Bharathiyar University, Coimbatore, TamilNadu, India-641014.
}

Email Address:

zionasudharsan@gmail.com (Shanthi)

mitrasureshkumar9@gmail.com (Kakarla Sai Mitravinda)

\section{To Cite this Article:}

S. Shanthi and Kakarla Sai Mitravinda, "Gender equality the need of the hour", International Journal of Language, Literature and Culture,1(1):1-4,2020.

Received: July 22, 2020. Revised: September 13,2020. Accepted: October 23,2020.

\begin{abstract}
Gender Equality is a very important thing needed for the development of a country. Gender equality has been convincingly appeared to invigorate economic growth, which is crucial for low-income countries. Gender equality among women and men alludes to the equivalent rights, obligations and open doors for women and men and boys and girls. Fairness doesn't imply that women and men will become same however that woman and man's privileges, duties and openings won't rely upon whether they are brought into the world male or female. Gender equality implies that the interests, needs and priorities of both women and men are taken into consideration recognizing the diversity of different groups of women and men. This paper clearly brings out the concept of gender equality in SDGs and provoking its importance in the well - being of a country.
\end{abstract}

Keywords: Gender, role, equality, men, women, SDG, thought-provoking, books

\section{Introduction}

It was 4.5 billion years ago. World confined to the belief that humanity is an essence of a single family, with everyone descended from a single pair of original ancestors-Adam and Eve. Adam and Eve, according to the creation myth of the Abrahamic religions, were the first man and woman. After eating the fruit, getting banned and becoming mortal, god blessed them to increase in number. Population increased so did gender discrimination leading to new rules and different cultures forcing people to follow those. Years rolled by but the concept of gender discrimination still continues. Gender equality is the condition of equivalent simple entry to assets and openings paying little mind to sex, including economic participation and decision-making. The general public is either men or women prevailing however not similarly predominant. Gender equality is the objective, while gender neutrality and gender equity are practices and perspectives that help in accomplishing the objective. The society is either men or women dominant but not equally dominant. Gender parity, which is employed to live gender balance during a given situation, can aid in achieving gender equality but isn't the goal in and of itself. Gender equality is quite equal representation; it's strongly tied to women's rights, and sometimes requires policy changes. As of 2017, the worldwide movement for gender equality has not incorporated the proposition of genders besides women and men, or gender identities outside the gender binary.

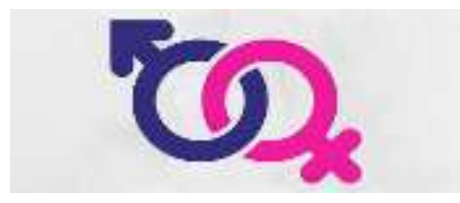

Figure 1. Typical gender representation

\section{Gender discrimination}

Gender inequality has been a social issue in India for hundreds of years. That in many parts of India, the birth of a woman child isn't welcomed may be a known fact. it's a known fact too, that discrimination starts from even before the girl child is born and sometimes, she is killed as a foetus, and if she manages to ascertain the sunshine of day, she is killed as an infant, which makes up the highly skewed child sex ratio where for each 1000 boys in India, there are only 908 girls. In such a scenario, it's but obvious that for myriad reasons, many women across the country are forced to drop out of faculty. Man, centric standards have stamped women as mediocre compared to men. A woman child is taken into account a burden and is usually not even allowed to ascertain the sunshine of the planet.

It's hard to imagine this state of affairs within the 21st Century when women have proved to be strong leaders in 
every field possible. From wrestling to business, the planet has been revolutionised by exceptional women leaders in fields that were until recently completely dominated by men. But in spite of such progress, even today, the girl child is discriminated against in most Indian households. The birth of a baby boy is widely known with great pomp and ardour, but the birth of a woman child is received with dismay.

The practice of female foeticide through sex selective abortion continues to be practiced in spite of the prenatal diagnostic procedure Act of 1994. In India the kid sex ratio is at rock bottom it's ever been with just 914 girls for each 1000 boys (Census, 2011). And this discrimination continues in every aspect. Be it education, health, protection or participation, the girl child is usually treated unequally. Indian society still hasn't been awakened to the importance of empowering the women. The statistics still portray female foeticide, girl child discrimination and gender bias.

\subsection{One among the 17 SDGs}

The Sustainable Development Goals are a universal call to action to finish poverty, protect the earth and improve the lives and prospects of everyone, everywhere. The 17 Goals were received by all UN Member States in 2015, as a piece of the 2030 Agenda for Sustainable Development.

Today, progress is being made in many places, but, overall, action to satisfy the Goals isn't yet advancing at the speed or scale required. 2020 must inaugurate a decade of ambitious action to deliver the Coals by 2030. With just ten years left to understand the Sustainable Development Goals, world pioneers at the SDC Summit in September 2019 included a time of activity and conveyance for practical turn of events, and promised to assemble financing, upgrade national execution and fortify establishments to understand the Goals by the deadline of 2030, abandoning no one.

The Sustainable Development Goals are:

- No Poverty

- Zero Hunger

- $\quad$ Good Health and Well-being

- Quality Education

- Gender Equality

- Clean Water and Sanitation

- Affordable and Clean Energy

- Decent Work and Economic Growth

- Industry, Innovation, and Infrastructure

- Reducing Inequality

- Sustainable Cities and Communities

- Responsible Consumption and Production

- Climate Action

- Life Below Water

- Life on Land

- $\quad$ Peace, Justice, and Strong Institutions

- Partnerships for the Goals

\subsection{Gender equality}

While the planet has accomplished advancement towards gender equality and women strengthening under the Millennium Development Goals (counting equivalent access to essential instruction among girls and boys), women despite everything endure segregation and brutality in each a piece of the planet.

Gender equality isn't only a fundamental right, but a necessary foundation for a peaceful, prosperous and sustainable world. Shockingly, right now, 1 of every 5 women and girls between the ages of 15-49 have announced encountering physical or sexual abuse by a close accomplice inside a year time frame and 49 nations at present haven't any laws shielding women from viciousness. Progress is happening regarding harmful practices like child marriage and FGM (Female Genital Mutilation), which has declined by $30 \%$ within the past decade, but there's still much work to be done to completely eliminate such practices. Furnishing women and girls with equivalent access to instruction, medicinal services, not too bad work, and portrayal in political and financial dynamic procedures will fuel supportable economies and advantage social orders and humankind on the loose. Executing new legitimate systems in regards to female equity inside the working environment and accordingly the destruction of unsafe practices focused at women is critical to closure the sex-based segregation predominant in numerous nations round the world.

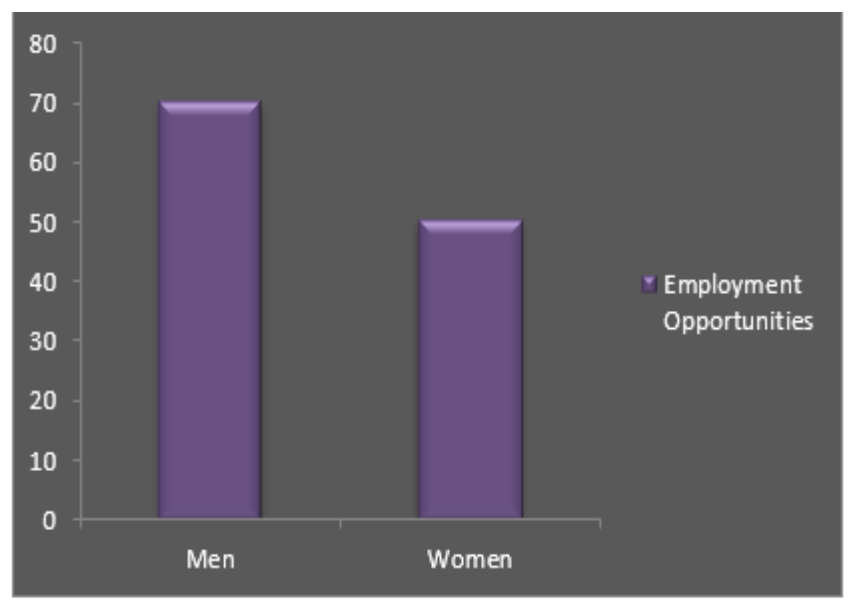

Figure 1. Employment opportunities

\section{Facts and figures}

- Clobally, 750 million women and girls were married before the age of 18 and at least 200 million women and girls in 30 countries have undergone FCM.

- The rates of girls between 15-19 who are subjected to FGM (female genital mutilation) in the 30 countries where the practice is concentrated have dropped from 1 in 2 girls in 2000 to 1 in 3 girls by 2017.

- In 18 countries, husbands can legally prevent their wives from working; in 39 countries, daughters and sons do not have equal inheritance rights; and 49 countries lack laws protecting women from domestic violence. 
- One in five women and girls, including 19 per cent of women and girls aged 15 to 49, have experienced physical and/or sexual violence by an intimate partner within the last 12 months. Yet, 49 countries have no laws that specifically protect women from such violence.

- While women have made important inroads into political office across the world, their representation in national parliaments at 23.7 per cent is still far from parity.

- In 46 countries, women now hold more than 30 per cent of seats in national parliament in at least one chamber.

- Only 52 per cent of women married or in a union freely make their own decisions about sexual relations, contraceptive use and health care.

- Clobally, women are just 13 per cent of agricultural land holders.

- Women in Northern Africa hold less than one in five paid jobs in the non-agricultural sector. The proportion of women in paid employment outside the agriculture sector has increased from 35 per cent in 1990 to 41 per cent in 2015.

- More than 100 countries have taken action to track budget allocations for gender equality.

- In Southern Asia, a girl's risk of marrying in childhood has dropped by over $40 \%$ since 2000.

(Source:

https://www.un.org/sustainabledevelopment/genderequality/)

\section{Goals}

- End all forms of discrimination against all women and girls everywhere

- Eliminate all forms of violence against all women and girls in the public and private spheres, including trafficking and sexual and other types of exploitation

- Eliminate all harmful practices, such as child, early and forced marriage and female genital mutilation

- $\quad$ Recognize and value unpaid care and domestic work through the provision of public services, infrastructure and social protection policies and the promotion of shared responsibility within the household and the family as nationally appropriate

- Ensure women's full and effective participation and equal opportunities for leadership at all levels of decision making in political, economic and public life

- Ensure universal access to sexual and reproductive health and reproductive rights as agreed in accordance with the Programme of Action of the International Conference on Population and Development and the Beijing Platform for Action and the outcome documents of their review conferences

- A Undertake reforms to give women equal rights to economic resources, as well as access to ownership and control over land and other forms of property, financial services, inheritance and natural resources, in accordance with national laws
- Enhance the use of enabling technology, in particular information and communications technology, to promote the empowerment of women

- Adopt and strengthen sound policies and enforceable legislation for the promotion of gender equality and the empowerment of all women and girls at all levels (Source:

https://www.un.org/sustainabledevelopment/genderequalityl)

\section{Steps taken in India to achieve gender equality}

- Swadhar and Short Stay Homes to give alleviation and restoration to desperate women and women in trouble.

- Working Women Hostels for guaranteeing safe settlement for working women from their place of living arrangement.

- Support to Training and Employment Program for Women (STEP) to guarantee reasonable work and pay age for minimized and resource less rustic and urban poor women the nation over.

- Rashtriya Mahila Kosh (RMK) to give small scale account administrations to realize the financial upliftment of poor women.

- National Mission for Empowerment of Women (NMEW) reinforce the general procedures that advance all-round Development of Women

- Rajiv Gandhi National Creche Scheme for Children of Working Mothers (counting single parent) to give day care offices to running a crèche of 25 youngsters in the age bunch 0-6 years from families having month to month pay of not as much as Rs 12,000 .

- One Stop Center to offer coordinated help and help to women influenced by brutality.

- Plan for Universalisation of Women Helpline proposed to give 24 hours prompt and crisis reaction to women influenced by savagery.

- Sabla Scheme for all encompassing advancement of juvenile girls in the age gathering of 11-18 years

- So as to fortify the procedure of sexual orientation planning the Ministry of Women and Child Development has been embraced different limit building measures for the authorities of the State Governments by sorting out preparing programs/workshops routinely.

Now, let us continue with those writers who are doing incredible work for gender equality. Together, they're standing by a bold demand to world leaders, urging them to make progress and provoking thoughts in Men to think about gender equality.

\section{Thought-provoking books on general equality}

\subsection{Know Why the Caged Bird Sings}


I Know Why the Caged Bird Sings is a 1969 life account depicting the early long periods of American essayist and artist Maya Angelou. The first in a seven-volume arrangement, it is a story about growing up that delineates how quality of character and an adoration for writing can help defeat bigotry and injury. The book starts when threeyear-old Maya and her more established sibling are sent to Stamps, Arkansas, to live with their grandma and closures when Maya turns into a mother at 16 years old. Over the span of Caged Bird, Maya changes from a casualty of bigotry with a feeling of inadequacy into a placid, honourable young lady fit for reacting to preference.

\subsection{The Moment of lift}

On the off chance that you need to lift a general public up, put resources into women.In this authentic and moving book, Gates follows her enlivening to the connection between ladies' strengthening and the soundness of social orders. She shows a portion of the gigantic open doors that exist right now to "turbo-charge" change. What's more, she gives basic and successful ways every single one of us can have any kind of effect. Persuaded that all ladies ought to be allowed to choose whether and when to have youngsters, Gates ventured out the worldwide stage to hold fast for family arranging. That progression propelled her into further endeavours: to guarantee ladies wherever approach each sort of occupation; to energize men around the world to share similarly in the weights of family work; to advocate for paid family leave for everybody; to kill sexual orientation predisposition in the entirety of its structures. All through, Gates acquaints us with her legends in the development towards balance, offers alarming information, shares moving discussions she's had with ladies from everywhere throughout the world-and shows how we would all be able to get included. An individual explanation of enthusiastic conviction, this book recounts Gates' excursion from an accomplice working off camera to one of the world's chief supporters for ladies, driven by the conviction that nobody ought to be prohibited, all lives have equivalent worth, and sexual orientation value is the switch that lifts everything.

\subsection{Little Women}

Little Women is a novel by American creator Louisa May Alcott (1832-1888) which was initially distributed in two volumes in 1868 and 1869. Alcott composed the book more than a while in line with her publisher. Following the lives of the four March sisters-Meg, Jo, Beth and Amy-the novel subtleties their section from youth to womanhood and is approximately founded on the lives of the writer and her three sisters. Scholars order Little Women as a self-portraying or semi-self-portraying novel. Little Women was a prompt business and basic achievement, with pursuers requesting to find out about the characters. Alcott immediately finished a subsequent volume (named Cood Wives in the United Kingdom, in spite of the fact that this name began from the distributer and not from Alcott). It was likewise effective. The two volumes were given in 1880 as a solitary novel named Little Women.

\section{Alpha girls}

A life-changing story of four ladies who, through coarseness and inventiveness, became stars in the ferocious, high-stakes, male overwhelmed universe of funding in Silicon Valley, and helped construct a portion of the premier organizations within recent memory. In Alpha Girls, grant winning writer Julian Guthrie takes pursuers behind the shut entryways of funding, an industry that changes economies and shapes how we live. We follow the lives and vocations of four ladies who were to a great extent worked out of history - as of recently.

Magdalena Yesil, who showed up in America from Turkey with $\$ 43$ to her name, would proceed to get her electrical science certificate from Stanford, discovered a portion of the main organizations to popularize web access, and help Marc Benioff manufacture Salesforce. Mary Jane Elmore went from the corn fields of Indiana to Stanford and on to the celebrated investment firm IVP - where she was one of the main ladies in the U.S. to make accomplice - just to be pulled once again from the unreasonable impediment by desires at home. Theresia Couw, an overachieving original Asian American from a common laborers town, ruled the foosball tables at Brown (she would later hesitantly let Sergey Brin win to help Accel Partners court Google), before she helped land and fabricate organizations including Facebook, Trulia, Imperva, and ForeScout. Sonja Hoel, a Southerner who turned into the primary lady contributing accomplice at white-glove Menlo Ventures, put resources into McAfee, Hotmail, Acme Packet, and F5 Networks. As her star was all the while ascending at Menlo, an individual emergency would transform her into a lobbyist short-term, motivating her to establish an all-ladies' speculation gathering and a national not-for-profit for young ladies.

\section{Becoming}

Becoming is the diary of previous United States first woman Michelle Obama distributed in 2018. Described by the writer as a profoundly close to home understanding, the book discusses her underlying foundations and how she discovered her voice, just as her time in the White House, her general wellbeing effort, and her job as a mother. The book is distributed by Crown and will be discharged in 24 dialects. One million duplicates will be given to First Book, an American philanthropic association which gives books to kids. It sold a larger number of duplicates than some other book distributed in the United States in 2018, breaking the record in only 15 days. More than eight years, Michelle Obama utilized her status as First Lady to solidly build up herself as a ground-breaking advocate for ladies and young ladies in the U.S. what's more, around the globe. Turning out to be isn't loaded up with sensational disclosures or political tattle and interest, however I discovered Mrs. Obama's story 
truly engaging-an African American young lady from the poor side of Chicago who through assurance and difficult work cut out a profoundly effective profession as an attorney until her better half's political aspirations constrained her to re-examine her own arrangements. Obama took advantage of the lucky break and the stage on offer to her and upset the First Lady Job, executing strategy change and enduring a hardship of analysis to be a motivation for ladies and young ladies around the world.

\section{Conclusion}

Now, let us continue with those writers who are doing incredible work for gender equality. Together, they're standing by a bold demand to world leaders, urging them to make progress and provoking thoughts in Men to think about gender equality. A nation can progress and attain higher development growth only when both men and women are entitled to equal opportunities. Women in the society are often cornered and are refrained from getting equal rights as men to health, education, decision-making and economic independence in terms of wages. The social structure that prevails since long in such a way that girls do not get equal opportunities as men. Women generally are the caregivers in the family. Because of this, women are mostly involved in household activities. There is lesser participation of women in higher education, decision-making roles, and leadership roles. This gender disparity is a hindrance in the growth rate of a country. When women participate in the workforce increases the economic growth rate of the country increases. Gender equality increases the overall wellbeing of the nation along with economic prosperity.

\section{References}

1 Patel, Vibhuti Amar, "Gender Equality and Human Rights", (May 21, 2014). Available at SSRN: https://ssrn.com/abstract=3182315 or http://dx.doi.org/1 $\underline{0.2139 / \text { ssrn.3182315 }}$

2 Abramson, R.Paul R. and Ronald Inglehart, "Value Change in Clobal Perspective", Ann Arbor, Mich: University of Michigan Press.

3 Almond, A.Gabriel and Sidney. Verba, "The Civic Culture; Political Attitudes and Democracy in Five Nations", Princeton, N.J: Princeton University Press.

4 Andersen and Kristi, "After Suffrage. Chicago: University of Chicago Press. Baxter, Sandra and Marjorie Lansing”, Women and Politics. Ann Arbor: University of Michigan Press.

5 Brill, Alida, "A Rising Public Voice: Women in Politics Worldwide. NY: Feminist Books”, Women's Representation in Parliament.' Party Politics, 1999; 5(1): 79-98.

6 Goot, Murray and Elizabeth Reid, "Women: If Not Apolitical, Then Conservative" Women and the Public Sphere, eds Janet Siltanen and Michelle Stanworth. London: Hutchinson.

7 Inglehart and Ronald, "Modernization and Postmodernization: Cultural, Economic and Political Change in 43 Societies", Princeton, NJ: Princeton University Press.

8 Norris and Pippa, "Politics and Sexual Equality", Boulder, Co: Rienner 